\title{
Characterization and Release Kinetics of Metronidazole Loaded Silver Nanoparticles Prepared from Carica papaya Leaf Extract
}

\author{
Tenderwealth Clement Jackson ${ }^{1}$, Akeem Ayodeji Agboke1, Edidiong Jumbo Udofa ${ }^{1}$, \\ Adaeze Salome Ucheokoro' ${ }^{2}$, Blessing Edidiong Udo', Nonye Linda Ifekpolugo ${ }^{1}$ \\ ${ }^{1}$ Department of Pharmaceutics and Pharmaceutical Technology, University of Uyo, Uyo, Akwa Ibom State, Nigeria \\ ${ }^{2}$ Department of Pharmaceutics and Pharmaceutical Technology, Gregory University, Uturu, Abia State, Nigeria \\ Email: *clementjackson@uniuyo.edu.ng
}

How to cite this paper: Jackson, T.C., Agboke, A.A., Udofa, E.J., Ucheokoro, A.S., Udo, B.E. and Ifekpolugo, N.L. (2019) Characterization and Release Kinetics of Metronidazole Loaded Silver Nanoparticles Prepared from Carica papaya Leaf Extract. Advances in Nanoparticles, 8, 47-54. https://doi.org/10.4236/anp.2019.83004

Received: July 27, 2019

Accepted: August 13, 2019

Published: August 16, 2019

Copyright $\odot 2019$ by author(s) and Scientific Research Publishing Inc. This work is licensed under the Creative Commons Attribution International License (CC BY 4.0).

http://creativecommons.org/licenses/by/4.0/

(c) (i) Open Access

\begin{abstract}
Silver nanoparticles were synthesized using eco-friendly method with the extract of Carica papaya as a reducing and stabilizing agent. Metronidazole 200 mg was loaded as a model drug to the silver nanoparticles. The percentage yield of the metronidazole nanoparticle was high (96.00\%). The entrapment efficiency $85.60 \%$ while the loading capacity was $8.90 \%$. Differential scanning calorimetry showed there was no interaction between the reducing agent and model drug. Characterization of the metronidazole malpractices using UVvis spectroscopy, zeta sizer, scanning electron microscopy (SEM) was performed. The UV-Vis spectroscopy showed surface plasmon resonance of $435 \mathrm{~nm}$ for the silver nanoparticle. The mean particle size was $250 \mathrm{~nm}$ while the polydispersity index was 0.22 . The metronidazole nanoparticle showed an extended and controlled release profile. The kinetics of release was zero-order $\left(\mathrm{R}^{2}=0.9931\right)$ for the metronidazole nanoparticle while the metronidazole normal release tablet followed Higuchi kinetics $\left(R^{2}=0.9745\right)$.
\end{abstract}

\section{Keywords}

Silver Nanoparticles, Eco-Friendly Synthesis, Characterization, Kinetics

\section{Introduction}

Nanoscience is the study of phenomena and manipulation of materials at atomic and molecular levels, where attributes are significantly different from those at a larger scale [1]. It is the science in which substances with small dimensions exhibit new physical phenomena, collectively known as quantum effects, which are size- 
dependent and remarkably different from the properties of large scale materials.

Nanotechnology is the application of nanoscience to meet industrial and commercial needs [1]. Nanotechnology can also be described as the design, characterisation, manufacturing and application of devices and systems by controlling shape and size at the nanometer range $(1-100 \mathrm{~nm})$.

Nanomedicine is simply the application of nanotechnology to medicine or healthcare delivery. It is the well-defined application of nanotechnology in the area of healthcare which involves disease diagnosis and treatment. Nanomedicine is a relatively new field of science and technology. By interacting with biological molecules at the nano level, nanotechnology opens up a vast field of research and application.

Silver nanoparticles were considered, in recent years, particularly attractive for the production of a new class of antimicrobials [2] [3] opening up a completely new way to combat a wide range of pathogenic bacteria.

The use of plants for the preparation of nanoparticles has gained more relevance in the last decade as the technique is simple, eco-friendly as it involves the use of plant extracts that contain biomolecules of medicinal value [4].

Various chemical and physical methods have been developed to prepare silver nanoparticles (AgNPs). Among them, the chemical reduction is the most widely used. These approaches are usually associated with the use of harzadous chemicals such as reducing agent, stabilizers, and organic solvents. This may also involve special requirements for the employed techniques such as high energy radiation and microwave irradiation [5].

The synthesis of silver nanoparticles has been carried out using fruit and extract of Citrus lanatus [6]. Synthesis of nanoparticles has also been done using Murraya koenigii [7], apple extract [8]. In spite of all these researches, there is a dearth of information on the synthesis of silver nanoparticles using Carica papaya as a reducing agent.

\section{Materials and Method}

Silver nitrate, Metronidazole powder (BDH Chemicals, England), and plant extract (Carica papaya) were the materials used. Other chemicals and reagents used were of laboratory and analytical grades.

\subsection{Plant Materials Collection and Processing}

Fresh leaves of Carica papaya (pawpaw) were collected from a local farm in Uyo, Akwa Ibom State, Nigeria. Plant species were identified and authenticated in the Department of pharmacognosy and Natural Medicine, University of Uyo. The plant leaves were thoroughly washed with tap water to avoid dusts and other unwanted materials accumulated on the leaves from their natural environment. The dust free leaves were pulverized and kept to dry under shade in the Pharmaceutics laboratory for $24 \mathrm{~h}$. The dried leaves were then powdered by using an electric blender. 


\subsection{Extraction Procedure}

$50 \mathrm{~g}$ of the powdered plant material was kept in a $500 \mathrm{~mL}$ conical flask and 250 $\mathrm{mL}$ of distilled water was added. The conical flask was covered with aluminium foil and kept in a reciprocating shaker for $24 \mathrm{~h}$ for continuous agitation at 150 rpm for thorough mixing. Then, the extract was filtered by using muslin cloth followed by Whatman no 1 filter paper. The resultant solution was kept for the nanoparticle synthesis.

\subsection{Synthesis of Silver Nanoparticles Using Aqueous Extracts of Carica papaya (Pawpaw Leaves) with Model Drug}

$10 \mathrm{~mL}$ of $1 \%$ silver nitrate $\left(\mathrm{AgNO}_{3}\right)$ was prepared by dissolving $0.1 \mathrm{~g}$ of silver nitrate $\left(\mathrm{AgNO}_{3}\right)$ in $10 \mathrm{~mL}$ of water, $0.2 \mathrm{~g}$ of metronidazole was added to the silver nitrate, followed by incorporation of $5 \mathrm{ml}$ of the Carica papaya leaf extract in drops under constant stirring using a magnetic stirrer assembly for $5 \mathrm{~min}$, to obtain $[\mathrm{Ag} / \mathrm{Drug})]^{+}$dispersion. $25 \mathrm{~mL}$ aliquot of a freshly prepared aqueous extract of Carica papaya leaves (reducing agent) was added to the resultant mixture and maintained at $40^{\circ} \mathrm{C}$ temperature for $24 \mathrm{~h}$. The resultant suspension of Ag/drug was lyophilized (Virtis 2KBTXL-75 Benchtop SLC Freeze Dryer) and subjected to further analysis.

\subsection{Characterization of Silver Nanoparticles}

\subsubsection{UV-Vis Spectroscopy to Determine Surface Plasmon Resonance for Silver Nanoparticles}

UV-Vis spectral analysis was done using a double-beam spectrophotometer (Hitachi, U-3010) with the samples dispersed in distilled water and kept in a quartz cuvette with a path length of $10 \mathrm{~mm}$.

\subsubsection{Percent Yield of Nanoparticles}

The percentage yield was calculated by dividing the actual yield by the initial weight of sample and multiplying the result by 100 percent.

\subsubsection{Entrapment Efficiency and Loading Capacity}

$50 \mathrm{mg}$ of the nanoparticle was dissolved in $50 \mathrm{ml}$ of Phosphate buffer ( $\mathrm{pH}$ 6.8). The suspension was ultra-centrifuged at $1500 \mathrm{rpm}$ at $40^{\circ} \mathrm{C}$ for $30 \mathrm{~min}$. The supernatant was analysed for metronidazole at $248 \mathrm{~nm}$. The loading capacity and entrapment efficiency were calculated for each nanoparticle using the formulae below:

Loading Capacity (L.C) $=$ \{weight of drug in the nanoparticle - weight of drug in the supernatant)/weight of nanoparticle $\times 100$

Entrapment Efficiency (E.E) $=$ (weight of drug in the nanoparticle - weight of drug in the supernatant)/weight of drug in nanoparticle $\times 100$

\subsubsection{Determination of Particle Size and Polydispersity Index}

The mean particle size (Z-average), Polydispersity Index (PDI) and zeta potential of the nanoparticles were determined by dynamic light scattering technique 
using a Zetasizer Ver.7.01 (Nano Zs 90, Malvern Instruments Ltd, UK). The freeze dried nanoparticle samples were dispersed in distilled water to obtain a proper scattering intensity before measurements at $25^{\circ} \mathrm{C}$. Triplicate determinations were made.

\subsubsection{Differential Scanning Calorimetry (DSC) and} Thermogravimetric Analysis

Thermogram of drug-polymer was employed (DSC-Shimadzu 50) for the determination of glass transition temperature $(\mathrm{Tg})$. About $1 \mathrm{mg}$ of sample was placed in aluminium pan and scanned over a temperature range of $25^{\circ} \mathrm{C}-250^{\circ} \mathrm{C}$ at the rate of $50^{\circ} \mathrm{C} / \mathrm{min}$. Each sample was subjected to three consecutive DSC scans.

\subsection{Morphological Studies of Nanoparticles Using Scanning Electron Microscopy (SEM)}

The nanoparticles were examined by Scanning Electron Microscope (SEM), Hitachi X650 (Tokyo, Japan).

\subsubsection{In Vitro Drug Release Studies}

Drug release studies were carried out separately in both simulated gastric fluid ( $\mathrm{pH}$ 1.2-acid buffer) and phosphate-buffered saline (PBS) solution ( $\mathrm{pH} 7.4$ ) using beaker magnetic stirrer assembly at $50 \mathrm{rpm}$ at a temperature of $37^{\circ} \mathrm{C} \pm$ $1^{\circ} \mathrm{C}$. At $30 \mathrm{~min}$ intervals $5 \mathrm{ml}$ samples were withdrawn and analyzed at $248 \mathrm{~nm}$ for metronidazole. A $5 \mathrm{ml}$ volume of fresh dissolution medium was added to maintain sink conditions after each withdrawal.

\subsubsection{In Vitro Release Kinetic Evaluation}

The dissolution data of each batch were fitted to various kinetic equations and mechanism of drug release investigated using Zero-order, First-order, and Korsmeyer-Peppas model respectively.

\section{Results}

The experiments were carried out in triplicates and the results obtained were expressed in Mean and Standard error of mean (Mean \pm SEM).

\section{Discussion}

\subsection{Percentage Yield, Entrapment Efficiency and Loading Capacity}

The percentage yield of $96 \%$ was appreciably high (Table 1). This may be due to polymer-drug ratio (7).

The entrapment efficiency and loading capacity of the nanoparticles are shown in Table 2. The entrapment efficiency was above $85.6 \%$ while the loading capacity was $8.9 \%$. Drug loading capacity is defined as the ratio of the practically determined percentage of drug content compared with actual or theoretical mass of drug used in the formulation of the nanoparticles [8]. The loading capacity is dependent on the polymer-drug combination and the method applied. Hydrophobic polymers tend to encapsulate larger amounts of hydrophobic drugs, 
Table 1. Percentage yield.

\begin{tabular}{cccc}
\hline & Theoretical yield $(\mathrm{g})$ & Actual yield $(\mathrm{g})$ & Percentage yield $(\%)$ \\
\hline Nano-MTZ & $0.25 \pm 0.01$ & $0.24 \pm 0.01$ & 96 \\
\hline
\end{tabular}

Table 2. Entrapment efficiency and loading capacity.

\begin{tabular}{ccc}
\hline & Entrapment efficiency (\%) & Loading capacity (\%) \\
\hline Nano-MTZ & $85.6 \pm 0.06$ & $8.9 \pm 0.12$ \\
\hline
\end{tabular}

whereas hydrophilic polymers entrap greater amounts of more hydrophilic drugs [8]. Several formulation factors, such as type of stabilizing agent and polymer-drug mass ratio will influence the extent of drug loading [9] [10].

\subsection{UV-Vis Spectroscopy}

The UV-Vis spectroscopy is utilized in the investigation of formation and stability of silver nanoparticles in solution [11].The characteristic change of colour from yellowish orange to dark brown is an indication of the formation of silver nanoparticles [12] [13]. The UV spectrum of $435 \mathrm{~nm}$ falls within the range 300 $480 \mathrm{~nm}$. This is in line with the findings of Jackson et al. in 2016 [14].

Metal nanoparticles including Silver nanoparticles, usually displays strong electromagnetic wave absorption spectra due to surface plasmon resonance in the visible range [15].

\subsection{Mean Particle Size and Polydispersity Index}

The mean particle size of metronidazole nanoparticle was $250 \mathrm{~nm}$ while the polydispersity index was 0.22 .

\subsection{Differential Scanning Calorimetry}

DSC thermograms showed there was no interaction between drug and the reducing agent in the nanoparticle (Figure 1).

\subsection{In Vitro Drug Release Studies}

The maximum drug release was $70 \%$ and $95 \%$ for normal release metronidazole tablets and metronidazole nanoparticle respectively (Figure 2 and Table 3 ).

\subsection{Determination of Release Kinetics}

To investigate the drug release kinetics, data obtained from in vitro dissolution studies were plotted into various kinetic models, which include zero-order, firstorder, Higuchiand korsemeyer kinetics. The results are presented in Table 4. Metronidazole nanoparticle released the drug by zero order kinetics, which is ideal for controlling drug delivery [16]. Metronidazole tablet followed Higuchi kinetics.

\section{Conclusion}

In this research work, metronidazole loaded silver nanoparticles were synthesised 


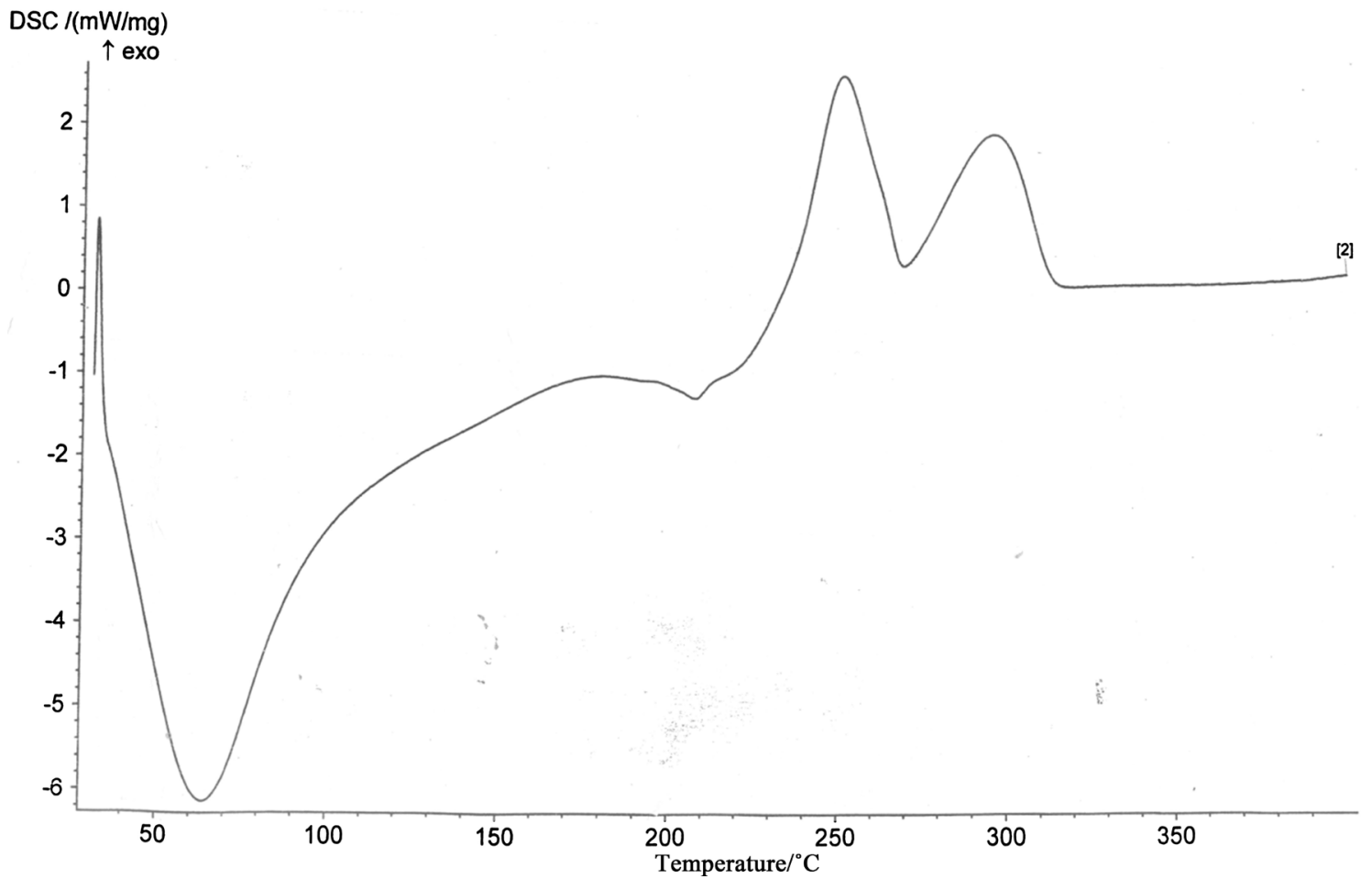

Figure 1. Themogram for Nano-MTZ.

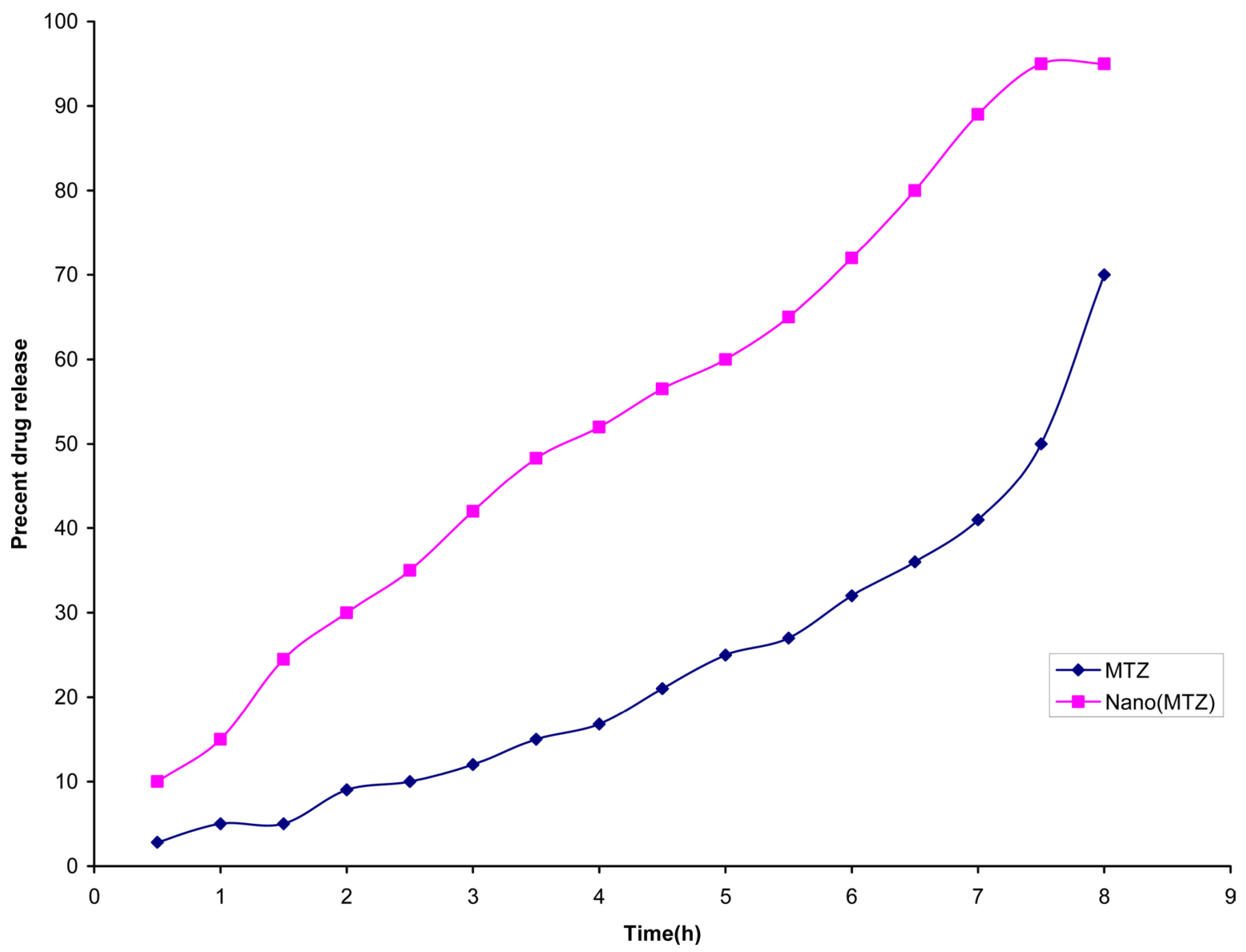

Figure 2. Drug Release Profiles of Normal release metronidazole and Metronidazole nanoparticles (Nano-MTZ). 
Table 3. Release parameters of Metronidazole tablets and Metronidazole nanoparticles.

\begin{tabular}{ccc}
\hline Parameters & MTZ & Nano-MTZ \\
\hline T50 & $7.5 \pm 0.12$ & $3.7 \pm 0.06$ \\
T70 & $8.0 \pm 0.23$ & $5.9 \pm 0.12$ \\
Maximum release (\%) & $70 \pm 1.15$ & $95 \pm 1.15$ \\
\hline
\end{tabular}

Table 4. Kinetics and mechanism of release for Metronidazole tablets and Metronidazole nanoparticles.

\begin{tabular}{cccccc}
\hline Formulations & Zero order $\left(\mathrm{R}^{2}\right)$ & First $\operatorname{Order}\left(\mathrm{R}^{2}\right)$ & Higuchi $\left(\mathrm{R}^{2}\right)$ & Korsemeyer $\left(\mathrm{R}^{2}\right)$ & $\mathrm{n}$-value $\left(\mathrm{R}^{2}\right)$ \\
\hline MTZ & 0.8847 & 0.7491 & 0.9745 & 0.9479 & 1.12 \\
Nano MTZ & 0.9931 & 0.8427 & 0.9693 & 0.9946 & 0.83 \\
\hline
\end{tabular}

successfully using eco-friendly method with the Carica papaya leaf extract as a reducing agent. UV-Vis spectroscopy confirmed the formation of silver nanoparticles with an absorption peak at $435 \mathrm{~nm}$ for the entire nanoparticle. The metronidazole nanoparticles showed extended release profiles. The kinetics of release was predominantly zero-order which is ideal for controlling release. The silver nanoparticles synthesized from Carica papaya can serve as effective drug delivery systems.

\section{Acknowledgements}

The authors are grateful to TET Fund, Nigeria. The staff members of Pharmaceutics and Pharmaceutical Technology, University of Uyo, Nigeria are also appreciated.

\section{Conflicts of Interest}

The authors declare no conflicts of interest regarding the publication of this paper.

\section{References}

[1] Agnieszka, Z., Wilczewska, K.N., Karolina, H. and Markiewicz, H.C. (2012) Nanoparticles as Drug Delivery Systems. Pharmacological Reports, 64, 1020-1037. https://doi.org/10.1016/S1734-1140(12)70901-5

[2] Dos Santos, C.A., Seckler, M.M., Ingle, A.P., Gupta, I., Galdiero, S., Galdiero, M., Gade, A. and Rai, M. (2014) Silver Nanoparticles: Therapeutical Uses, Toxicity, and Safety Issues. Journal of Pharmaceutical Sciences, 103, 1931-1944.

[3] Fayaz, A.M., Balaji, K., Girilal, M., Yadav, R., Kalaichelvan, P.T. and Venketesan, R. (2010) Biogenic Synthesis of Silver Nanoparticles and Their Synergistic Effect with Antibiotics: A Study against Gram-Positive and Gram-Negative Bacteria. Nanomedicine: Nanotechnology, Biology and Medicine, 6, 103-109. https://doi.org/10.1016/j.nano.2009.04.006

[4] Rai, M.K., Deshmukh, S.D., Ingle, A.P. and Gade, A.K. (2012) Silver Nanoparticles: The Powerful Nanoweapon against Multidrug-Resistant Bacteria. Journal of Applied Microbiology, 112, 841-852. https://doi.org/10.1111/j.1365-2672.2012.05253.x 
[5] Rai, M., Deshmukh, S.D., Ingle, A.P., Gupta, I.R., Galdiero, M. and Galdiero, S. (2014) Metal Nanoparticles: The Protective Nanoshield against Virus Infection. Critical Reviews in Microbiology, 42, 45-56. https://doi.org/10.3109/1040841X.2013.879849

[6] Roy, S. and Das, T.K. (2015) Plant Mediated Green Synthesis of Silver Nanoparticles-A Review. International Journal of Plant Biology \& Research, 3, 1044.

[7] Rao, B. and Tang, R.-C. (2017) Green Synthesis of Silver Nanoparticles with Antibacterial Activities Using Aqueous Eriobotrya Japonica Leaf Extract. Advances in Natural Sciences: Nanoscience and Nanotechnology, 8, Article ID: 015014. https://doi.org/10.1088/2043-6254/aa5983

[8] Ndikau, M., Noah, N.M., Andala, D.M. and Masika, E. (2017) Green Synthesis and Characterization of Silver Nanoparticles Using Citrullus lanatus Fruit Rind Extract. International Journal of Analytical Chemistry, 2017, Article ID: 8108504. https://doi.org/10.1155/2017/8108504

[9] Liu, D.-G., Wu, Q.-L., Chen, H.-H. and Chang, P.R. (2009) Transitional Properties of Starch Colloid with Particle Size Reduction from Micro- to Nanometer. Journal of Colloid and Interface Science, 339, 117-124. https://doi.org/10.1016/j.jcis.2009.07.035

[10] Dhanalekshmi, U.M., Poovia, G. and Reddy, P.N. (2012) In-Vitro Observation of Repaglinide Engineered Polymeric Nanoparticles. Digest Journal of Nanomaterials and Biostructures, 7, 1-18.

[11] Peng, D.-M., Huang, K.-L., Liu, Y.-F. and Liu, S.-Q. (2007) Preparation of Novel Polymeric Microspheres for Controlled Release of Finasteride. International Journal of Pharmaceutics, 342, 82-86. https://doi.org/10.1016/j.ijpharm.2007.05.002

[12] Dhanalekshmi, U.M., Poovi, G., Kishore, N. and Reddy, P.N. (2010) In Vitro Characterization and in Vivo Toxicity Studies of Repaglinide Loaded Poly(Methyl Methacrylate) Nanoparticles. International Journal of Pharmaceutics, 396, 194-203. https://doi.org/10.1016/j.ijpharm.2010.06.023

[13] Priyadarshni, K.C. and Mahalingam, P.U. (2017) Antimicrobial and Anticancer Activity of Silver Nanoparticles from Edible Mushroom: A Review. Asian Journal of Pharmaceutical and Clinical Research, 10, 37-41. https://doi.org/10.22159/ajpcr.2017.v10i3.16027

[14] Jackson, T.C., Agboke, A.A., Jackson, I.L. and Ekpuk, E.J. (2016) Biosynthesis of Silver Nanoparticles Using Murraya koenigii and Acacia Gum. International Journal of Research in Pharmacy and Biosciences, 3, 29-32.

[15] Amin, M., Anwar, F., Janjua, M.R., Iqbal, M.A. and Rashid, U. (2012) Green Synthesis of Silver Nanoparticles through Reduction with Solanum xanthocarpum $L$. Berry Extract: Characterisation, Antimicrobial and Urease Inhibitory Activities against Helicobacter pylori. International Journal of Molecular Sciences, 13, 9923-9941. https://doi.org/10.3390/ijms13089923

[16] Ali, Z.A., Yahya, I.R., Sekaran, S.D. and Puteh, R. (2016) Green Synthesis of Silver Nanoparticles Using Apple Extract and Its Antibacterial Properties. Advances in Materials Science and Engineering, 2016, Article ID: 4210296.

https://doi.org/10.1155/2016/4102196 